\title{
NOTE ON SOME UPPER BOUNDS FOR THE CONDITION NUMBER
}

\section{GuANGHui CHENG}

Abstract. In this letter, some lower bounds for the smallest singular value of the nonsingular matrix are established. In addition, we also proposed some upper bounds on the condition number of a matrix which are the better than the bound proposed by Guggenheimer et al. [College Math. J. 26(1) (1995) 2-5]. To illustrate our bounds, some examples are also given.

Mathematics subject classification (2010): 15A18, 65F35.

Keywords and phrases: singular value; condition number; Frobenius norm; nonsingular matrix.

\section{REFERENCES}

[1] H.W. Guggenheimer, A.S. Edelman And C.R. Johnson, A simple estimate of the condition number of a linear system, College Mathematics Journal 26, 1 (1995), 2-5.

[2] A.D. GÜNGÖR, Erratum to "An upper bound for the condition number of a matrix in spectral norm" [J. Comput. Appl. Math. 143 (2002) 141-144], Journal of Computational and Applied Mathematics 234, 1 (2010), 316.

[3] T.Z. HuAng, Estimation of $\left\|A^{-1}\right\|_{\infty}$ and the smallest singular value, Computers \& Mathematics with Applications 55, 6 (2008), 1075-1080.

[4] J. K. Merikos Ki, U. Urpala, A. Virtanen, T. Y. Tam and F. Uhlig, A best upper bound for the 2-norm condition number of a matrix, Linear Algebra and its Applications 254, 1-3 (1997), 355-365.

[5] G. PiazZA AND T. Politi, An upper bound for the condition number of a matrix in spectral norm, Journal of Computational and Applied Mathematics 143, 1 (2002), 141-144.

[6] O. RoJo, Further bounds for the smallest singular value and the spectral condition number, Computers \& Mathematics with Applications 38, 7-8 (1999), 215-228.

[7] Y.S. YU AND D.H. GU, A note on a lower bound for the smallest singular value, Linear Algebra and its Applications 253, 1-3 (1997), 25-38.

[8] L.M. ZOU AND Y. JIANG, Estimation of the eigenvalues and the smallest singular value of matrices, Linear Algebra and its Applications 433, 6 (2010), 1203-1211.

[9] L.M. Zou, A lower bound for the smallest singular value, Journal of Mathematical Inequalities 6, 4 (2012), 625-629. 